\title{
Selective local synthesis of nanowires on a microreactor chip ${ }^{\text {is }}$
}

\author{
Wei-Chih Lin ${ }^{\mathrm{a}, \mathrm{b}, *}$, Yao-Joe Yang ${ }^{\mathrm{a}}$, Gen-Wen Hsieh ${ }^{\mathrm{b}}$, Ching-Hsiang Tsai ${ }^{\mathrm{c}}$, \\ Chien-Chen Chen ${ }^{\mathrm{a}}$, Chao-Chiun Liang ${ }^{\mathrm{b}}$ \\ a Department of Mechanical Engineering, National Taiwan University, Taipei, Taiwan \\ ${ }^{\mathrm{b}}$ Industrial Technology Research Institute (ITRI), Hsinchu, Taiwan \\ ${ }^{\mathrm{c}}$ Department of Nanomechanics, Tohoku University, Miyagi, Japan
}

Received 15 June 2005; received in revised form 13 January 2006; accepted 9 March 2006

Available online 11 May 2006

\begin{abstract}
This work presents a novel synthesis process for selectively locally growing nanowires on a microreactor chip fabricated by MEMS processes. Nanowires are synthesized in a microchamber by patterned catalysts, reactive gases, and integrated microheaters heating the catalysts to the required temperatures for nanowires growth. Using a field emission scanning electron microscope (FE-SEM) and a transmission electron microscope (TEM), this paper confirms that the synthesized structures are multi-wall carbon nanotubes (CNT). The average diameter of the CNTs is about $16.93 \mathrm{~nm}$ and the length is about 100-200 nm. Applying this novel process, the location of the synthesized CNTs can be positioned onto the microheaters in a controllable way. Furthermore, by means of the developed microheater modeling, the chemical vapor deposition CNTs synthesis process can be conducted in low temperature and a low voltage as small as $7 \mathrm{~V}$ is required for the microheaters. The proposed synthesis approach makes it possible to integrate CNTs on IC devices by effectively diminishing thermal damage during their growing process.
\end{abstract}

(C) 2006 Elsevier B.V. All rights reserved.

Keywords: Carbon nanotubes (CNTs); Nanowires; Microreactor; Microheater

\section{Introduction}

The researches on carbon nanotubes (CNT) have received significant attention since it was discovered by Iijima [1]. CNT mainly consist of single- or multiple-walled graphene layers. Using different conditions of chemical reactions or catalysts, it is possible to synthesize single-walled carbon nanotubes (SWNT) or multi-walled carbon nanotubes (MWNT), with radii of about $1-100 \mathrm{~nm}$ and lengths of about $0.1-100 \mu \mathrm{m}$. The fabrication (synthesis) methods can be classified as three types: (1) the plasma discharging method [2,3], (2) the laser ablation method [4], and (3) the metal-catalyzed thermal chemical vapor deposition method. For the plasma discharging method, DC electric field is applied between two graphite electrodes in a chamber with inert gas, such as hydrogen $\left(\mathrm{H}_{2}\right)$ or argon $(\mathrm{Ar})$. The CNT is

\footnotetext{
is This paper was presented at the transducers' 05 conference, held in Seoul, Korea, 5-9 June, 2005, and is an expansion of the abstract as printed in the Technical Digest of this meeting.

* Corresponding author. Tel.: +88 635913 149; fax: +88 635820266 .

E-mail address: weichihlin@itri.org.tw (W.-C. Lin).
}

synthesized as plasma discharge occurs between the two electrodes. For the laser ablation method, the focused high-energy beam is used to sublime graphite in a high-temperature furnace in order to form CNT. For the metal-catalyzed thermal CVD method, the CNT is synthesized in a furnace by the pyrolysis of $\mathrm{C}_{2} \mathrm{H}_{2}$ or $\mathrm{CH}_{4}$ with catalysts $\mathrm{Fe}, \mathrm{Co}$, and $\mathrm{Ni}$.

The most important conditions to synthesize CNT using the metal-catalyzed thermal CVD method are the process temperature, the catalysts and the reaction gases. At this moment, this synthesis technique is relatively mature. However, the integration of the synthesis process with IC processes is still very difficult [5-8]. It is because the CNT is usually synthesized after IC fabrication processes, and the fabricated circuitry can be easily damaged during the CNT synthesis process which requires high temperature.

Englander et al. $[9,10]$ employed polysilicon microheater device, which is fabricated by MEMS technology, to synthesize CNT on the microheater surface in a traditional CNT CVD chamber. In this work, we develop a microreactor chip by using MEMS processes. This chip consists of metallic microheater structures and a miniaturized CNT CVD furnace, which serves 


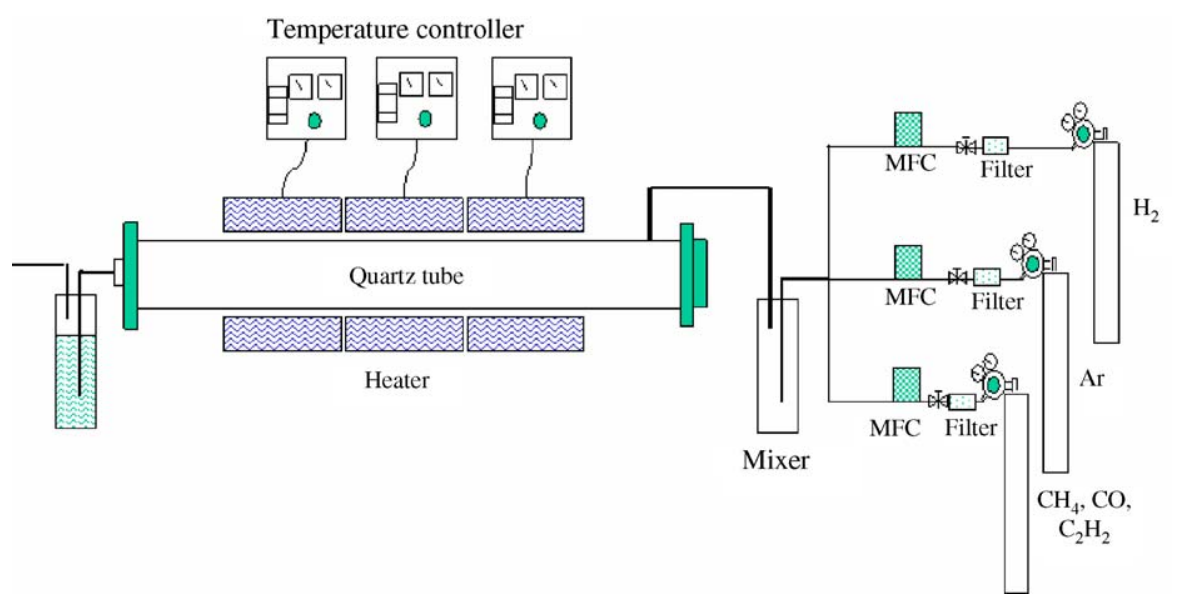

Fig. 1. A traditional CNT synthesis system.

as a microchamber. CNT can be locally selectively synthesized on the surfaces, which are defined by patterning catalysts using lithography technique. This approach can effectively avoid heating up the whole chip during CNT synthesis so that it is potentially compatible with IC processes $[11,12]$.

\section{Preliminary experiment results}

\subsection{CNT synthesis conditions}

There are many process parameters for synthesizing CNT. Therefore, we use traditional equipment for preliminary study on process parameters $[13,14]$. Fig. 1 shows the schematic of the synthesis system. The reactor is a quartz furnace of $120 \mathrm{~cm}$ in length and $5 \mathrm{~cm}$ in diameter, with a heater and a temperature controller (West, 3810). The maximum achievable temperature is $1200^{\circ} \mathrm{C}$, and the maximum temperature elevation rate is $15^{\circ} \mathrm{C} / \mathrm{min}$. Without pre-heating, the reactants $\left(\mathrm{Ar}, \mathrm{C}_{2} \mathrm{H}_{2}\right.$, and $\mathrm{H}_{2}$ ) are supplied to a mixer before entering the furnace. Flow meters (Hastings, Model 400) are used to control the flow rates of the reactants.

A Ni catalyst layer of $30 \mathrm{~nm}$ in thickness is deposited and patterned on a substrate. Then the substrate is put into the quartz furnace. As the temperature is stable at $535^{\circ} \mathrm{C}$, Ar gas of flow rate $2000 \mathrm{sccm}$ is supplied into the tube for $10 \mathrm{~min}$. The mixture of $\mathrm{Ar}$ and $\mathrm{H}_{2}(800 / 150 \mathrm{sccm})$ is supplied into the tube for $20 \mathrm{~min}$ before the start of the reaction. Then $\mathrm{C}_{2} \mathrm{H}_{2}$ and $\mathrm{H}_{2}(40 / 150 \mathrm{sccm})$ is supplied into the furnace for the CNT CVD reaction. After 10 min, the supply of $\mathrm{C}_{2} \mathrm{H}_{2}$ and $\mathrm{H}_{2}$ is stopped, and the heating is also terminated. The wafer can be removed from the furnace for inspection after the system cools down to around $100^{\circ} \mathrm{C}$. Fig. 2 shows the synthesized CNT on the patterned area. The length and the radius of the CNT are about $10 \mu \mathrm{m}$ and $100 \mathrm{~nm}$, respectively. Based on the preliminary study, the most important process parameters are the minimum reaction temperature, the flow rate of the reactant gases, the mixture-ratio of the reactant gases, and thickness of the catalyst layer.

\subsection{Thermal analysis for the microheater}

We also use the Coventorware to study the microheater's thermal characteristics, such as the temperature-voltage relationship and the optimal dimensions/shapes of the microheater. Fig. 3(a) shows the simulated temperature distribution by the Coventorware. The model includes a Ti layer of $50 \mu \mathrm{m} \times 50 \mu \mathrm{m} \times 0.5 \mu \mathrm{m}$, an $\mathrm{Au}$ interconnect layer of $125 \mu \mathrm{m} \times 50 \mu \mathrm{m} \times 0.5 \mu \mathrm{m}$, a nitride layer of $300 \mu \mathrm{m} \times 200 \mu \mathrm{m} \times 1.5 \mu \mathrm{m}$. The thickness of the substrate is $300 \mu \mathrm{m}$. The bottom of the substrate is fixed at $300 \mathrm{~K}$. Natural convection effect is also considered in the model. The simulated result is shown in Fig. 3(b). The heater reaches $900 \mathrm{~K}$ as the applied voltage is about $2.7 \mathrm{~V}$.
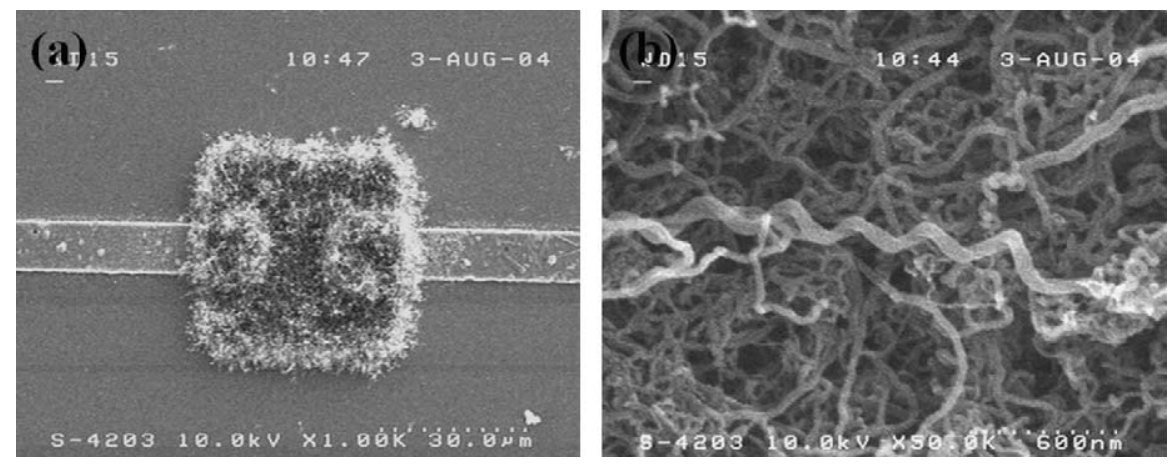

Fig. 2. The CNT synthesized using the traditional CVD method. 
(a)

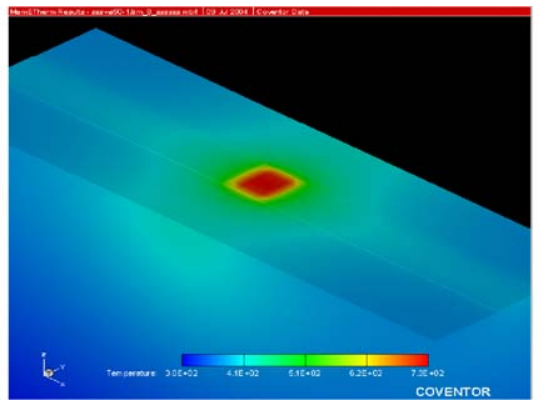

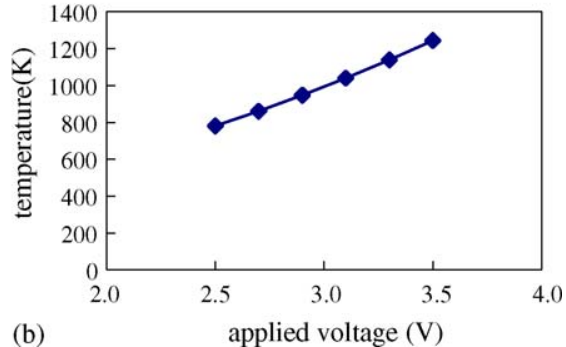

(b)

Fig. 3. (a) The solid model and the temperature of the microheater. (b) The simulated temperature-voltage relationship.
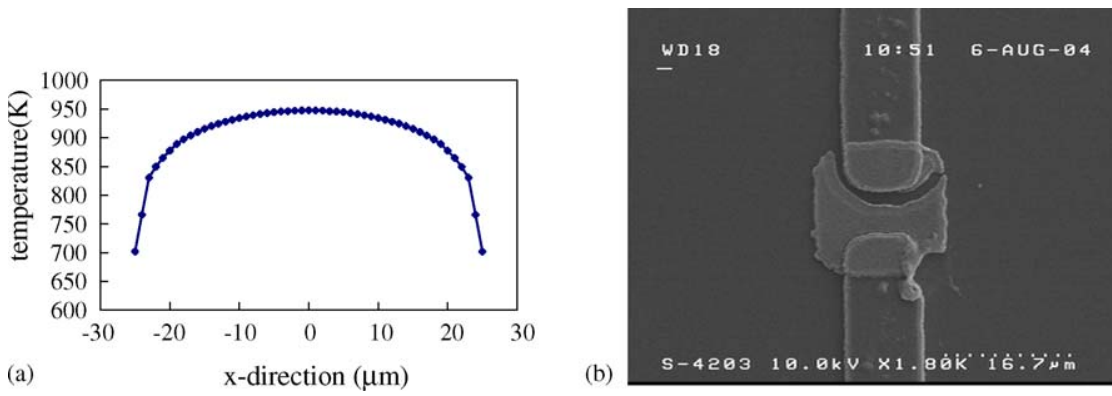

Fig. 4. (a) The temperature distribution on the microheater. (b) The SEM picture of a device that is damaged by an applied voltage beyond the maximum permission.

The spatial variation of temperature on the top surface of a heater $(2.7 \mathrm{~V})$ is shown in Fig. 4(a). This figure indicates that the area with relatively uniform temperature distribution is about $30 \mu \mathrm{m} \times 30 \mu \mathrm{m}$. Fig. 4(b) shows the SEM picture of a device that was damaged by an applied voltage of $5 \mathrm{~V}$. Based on the simulations, the maximum allowable voltage is below $4 \mathrm{~V}$, as indicated Fig. 3(b). Note that the simulated allowable voltage is a little lower than the measured results because the simulations assume that the gases are stationary so that the convection effect is underestimated.

\section{Microreactor}

\subsection{Fabrication of the microreactor}

Fig. 5(a)-(c) show schematics of the components and the integration of the whole device. Fig. 5(a) is the microheater chip, Fig. 5(b) is the cap of the microreactor, and Fig. 5(c) is the packaged device after the heater and the cap is bonded using the anodic bonding process. As shown in the figure, the reactant gases are supplied into the reaction chamber through the inlet. The external voltage source is connected to the microheater through the etched holes on the cap.

Figs. 6 and 7 show the processes of the microreactor chip, which include a surface-micromachining for the microheater, and a bulk-micromachining for a Pyrex-glass cap. For the microheater, two metal layers for the conductive wires, which consist of a $0.5 \mu \mathrm{m}$ gold film and a $50 \mathrm{~nm}$ chromium film, are sputtered and patterned by the lift-off technique. An RIE patterning, which is supposed to prevent the contact problem in the electrodes with microheater, is performed on the nitride layer before the lift- off process. Then a $0.5 \mu \mathrm{m}$ titanium layer for the microheater and a $30 \mathrm{~nm}$ nickel layer (catalyst) are sputtered and patterned by lift-off. The Pyrex-glass cap is fabricated by the techniques of lithography and laser machining. Finally, the silicon chip is bonded with the Pyrex-glass cap by anodic bonding.

Fig. 8 shows the pictures of the fabricated microreactor device. Fig. 8(a) is the microheater. The smaller picture on the top-left corner is the whole microheater chip. Fig. 8(b) is the Pyrex cap. Fig. 8(c) is the finished product after anodic bonding. The temperature and the voltage for the anodic bonding are $200^{\circ} \mathrm{C}$ and $300 \mathrm{~V}$, respectively.

(a)

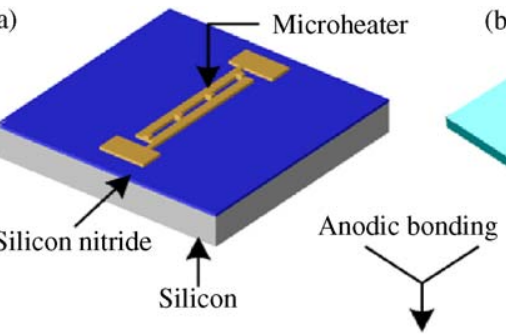

(b)

(c)

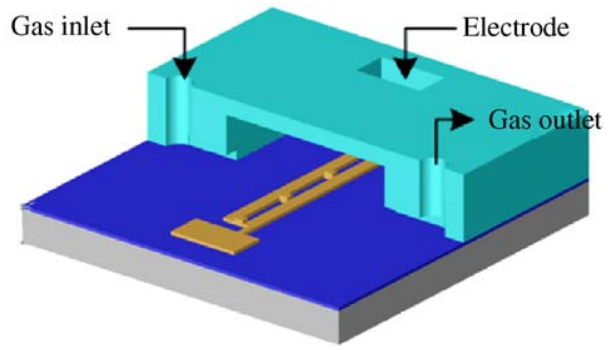

Fig. 5. The components and the assembly of the microreactor. 
(a) Deposition LPCVD $\mathrm{Si}_{3} \mathrm{~N}_{4}$ (a)

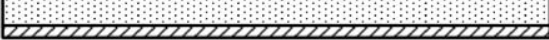

(b) RIE etching

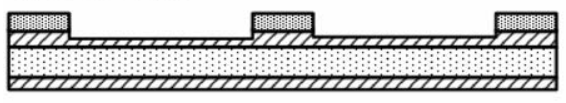

(c) Conducting wire pattern

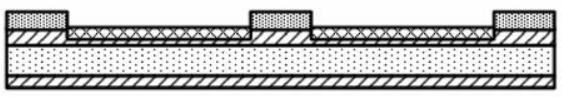

(d) Heater and catalyst pattern

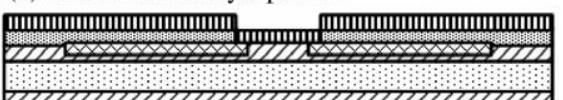

(e) Lift-off
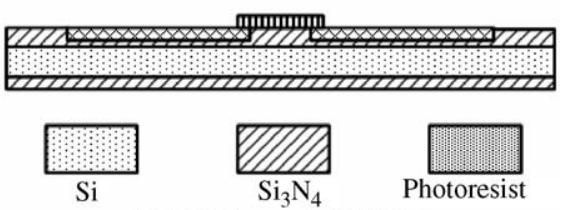

Photoresist

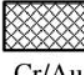

Fig. 6. The process flow of the microheater chip.

(a) Micro-chamber/ channel pattern

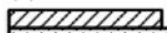

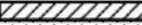

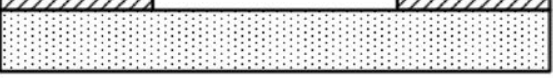

(b) Micro-chamber/ channel pattern

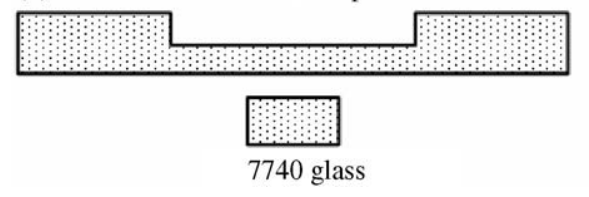

(c) Inlet/Outlet hole pattern

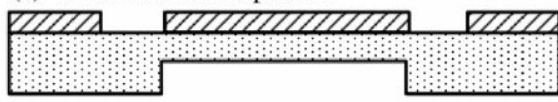

(d) Inlet/Outlet hole manufacture

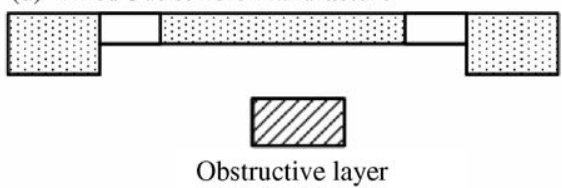

Fig. 7. The process flow of the cap for the microreactor.

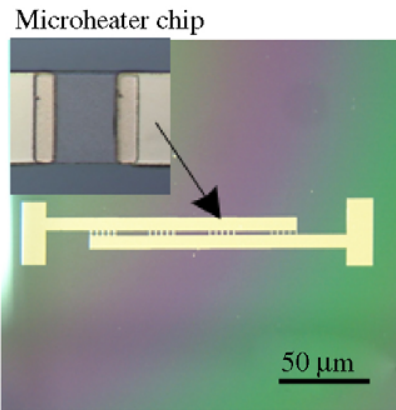

(a)

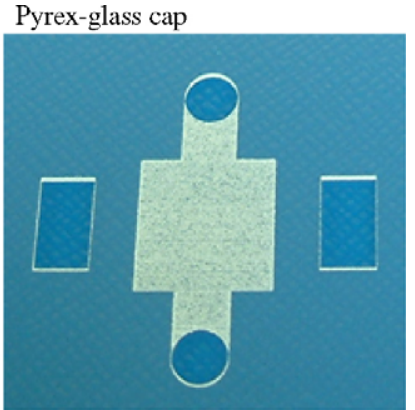

(b)

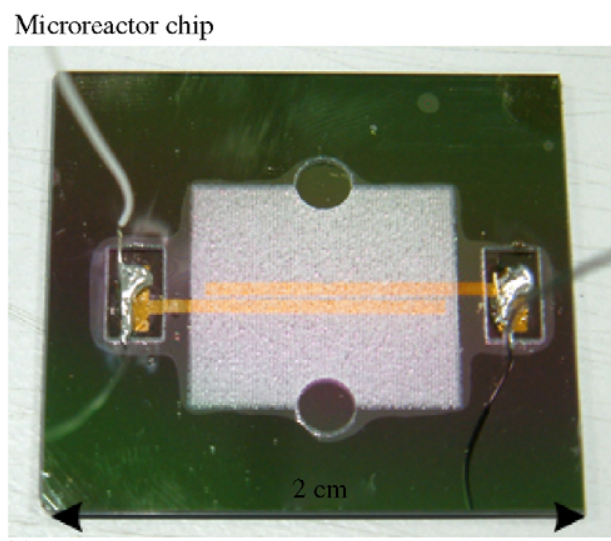

(c)

Fig. 8. (a) The microheater. The smaller picture on the top-left corner is the whole microheater chip. (b) The Pyrex cap. (c) The finished product after anodic bonding. 


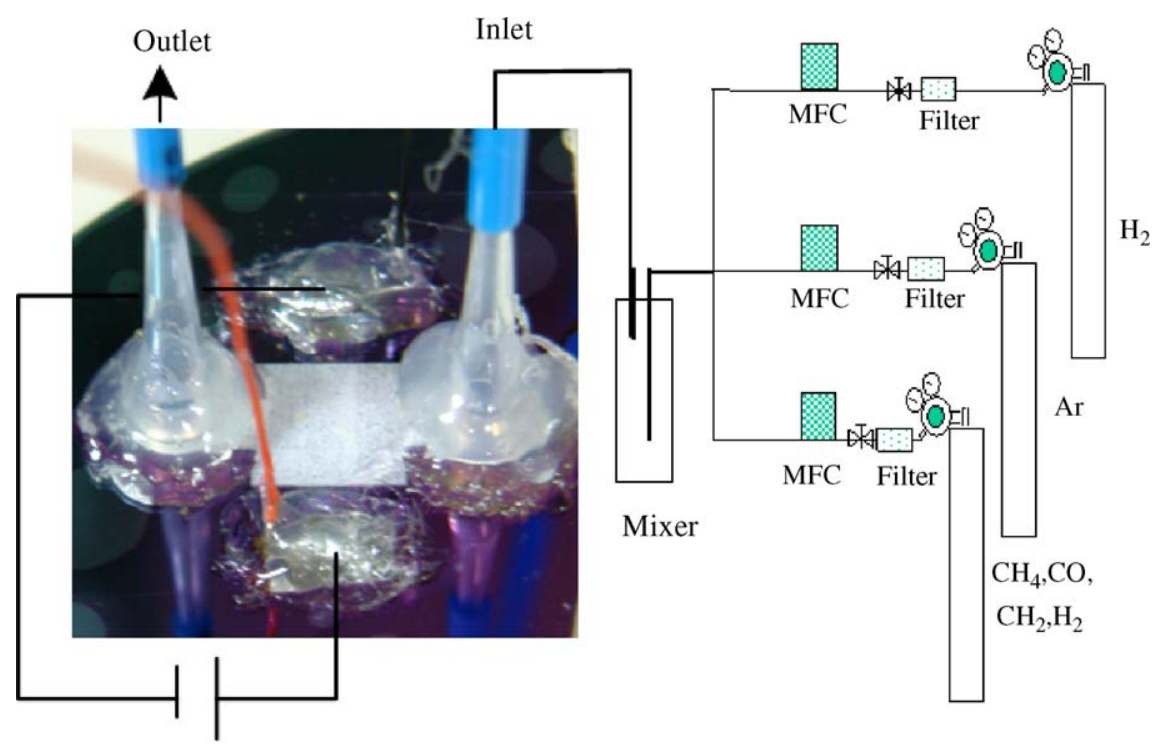

Fig. 9. The experimental setup of the CVD CNT microreactor.

\subsection{Experimental setup}

Fig. 9 shows the experimental setup of the microreactor for the CVD CNT synthesis. Based on the preliminary study of CNT synthesis using a traditional CVD chamber, the reaction process is divided into three steps:

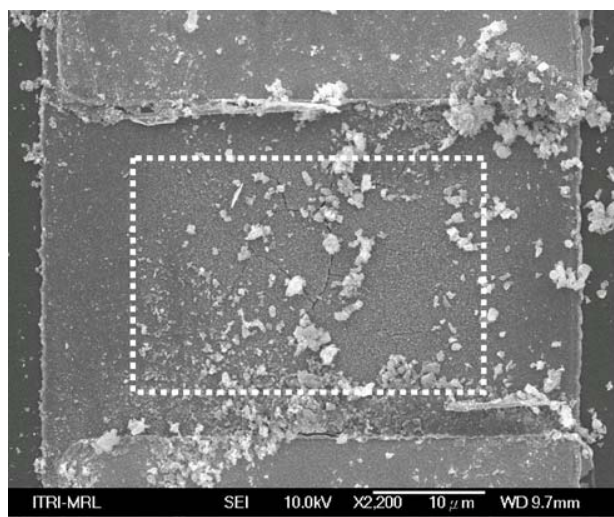

(a)
(1) Supplying $\mathrm{H}_{2}(10 \mathrm{sccm} / \mathrm{min})$ and $\mathrm{Ar}(75 \mathrm{sccm} / \mathrm{min})$ for $5 \mathrm{~min}$, and heating the chamber by applying voltage with $0.1 \mathrm{~V} / \mathrm{s}$ up to $3 \mathrm{~V}$.

(2) Supplying $\mathrm{C}_{2} \mathrm{H}_{2}(50 \mathrm{sccm} / \mathrm{min})$, and increasing the voltage from 3 to $7 \mathrm{~V}$ with $0.1 \mathrm{~V} / \mathrm{s}$ for $40 \mathrm{~s}$. The CVD CNT synthesis process starts.

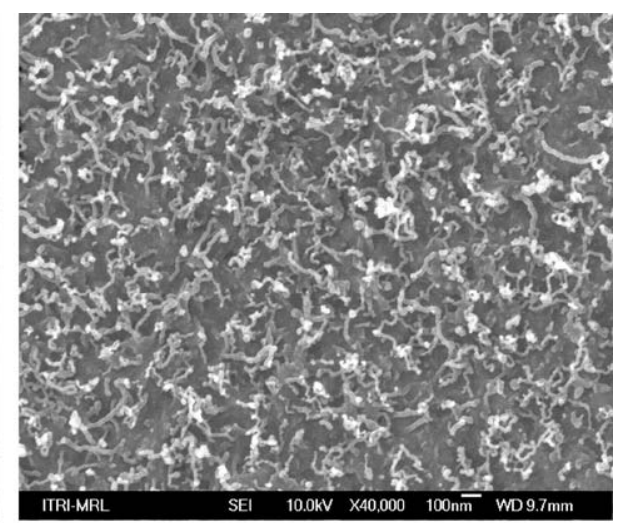

(b)

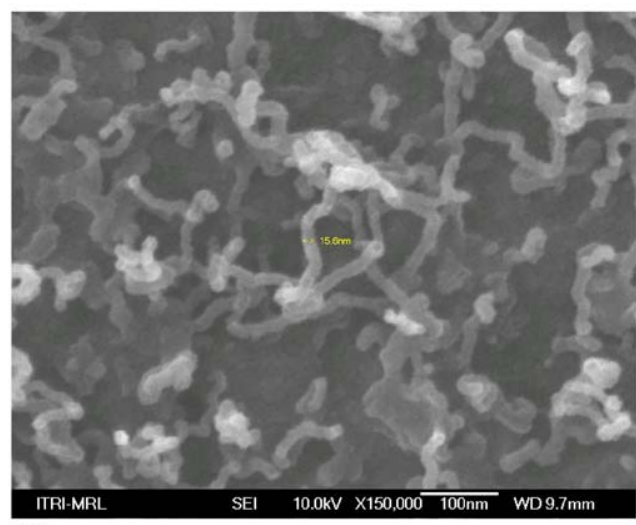

(c)

Fig. 10. The FE-SEM pictures of synthesized nanowires using this microreactor. 
(3) Stopping supplying $\mathrm{C}_{2} \mathrm{H}_{2}$ and disconnecting the applied voltage. The reactor cools down.

\section{Results and discussion}

The key process parameters are the catalyst, the synthesized gases as well as the heating condition. A voltage of $7 \mathrm{~V}$ is applied to the microheater for the reaction of nickel catalyst with the synthesized gases including $\mathrm{H}_{2}(10 \mathrm{sccm} / \mathrm{min}), \mathrm{Ar}$ $(75 \mathrm{sccm} / \mathrm{min})$, and $\mathrm{C}_{2} \mathrm{H}_{2}(50 \mathrm{sccm} / \mathrm{min})$. Fig. 10(a)-(c) show the synthesized CNT by the microreactor chip. Note that these pictures are obtained using a FE-SEM (JEOL, JSM-6500F). Fig. 10(a) shows the growth of nanotubes is localized on the center region (about $30 \mu \mathrm{m} \times 30 \mu \mathrm{m}$ ) of the microheater whose dimension is $50 \mu \mathrm{m} \times 50 \mu \mathrm{m}$. This result is consistent with the simulated results shown in Fig. 4. Fig. 10(b) is the 40,000-time-magnified picture of the dotted area in Fig. 10(a). Fig. 10(c) indicates that the diameters of the synthesized CNT are about $15.6 \mathrm{~nm}$ and their lengths are about $100-200 \mathrm{~nm}$.

Fig. 11 is a statistical dimensional distribution of synthesized CNT from 40 samplings of CNT diameter data. The CNT diam-

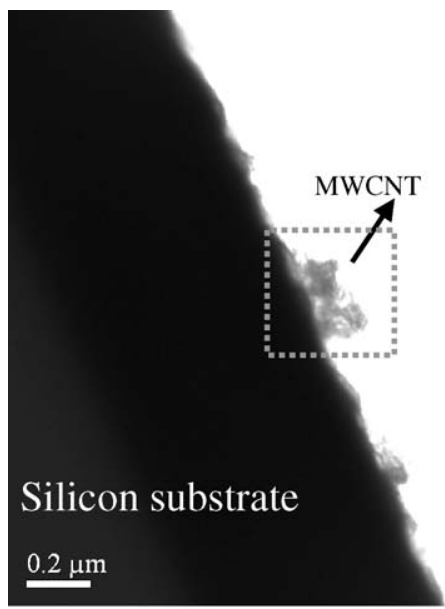

(a)

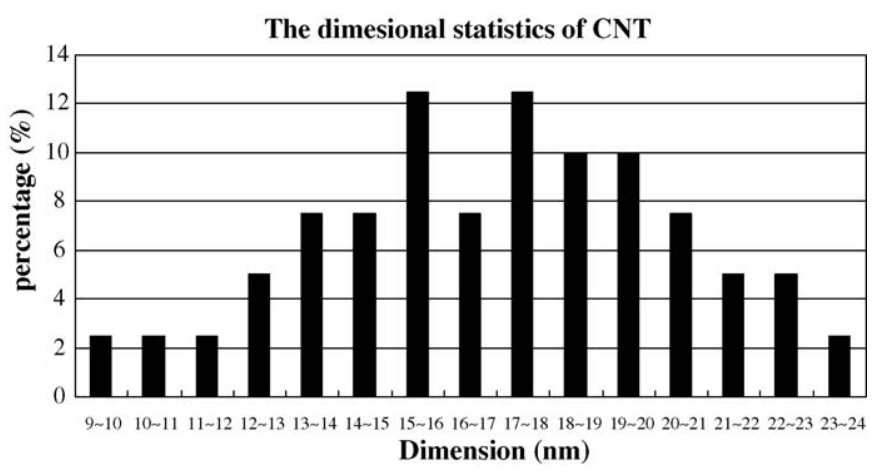

Fig. 11. Statistical distribution of dimension from 40 samplings of the CNT diameter data.

eters distribute between 9 and $24 \mathrm{~nm}$, while higher distributions occur from 13 to $21 \mathrm{~nm}$. Besides, the average diameter of CNT is $16.93 \mathrm{~nm}$ and the lengths are about $100-200 \mathrm{~nm}$.

Fig. 12(a)-(c) are the TEM pictures of the synthesized CNT. In order to characterize the CNT crystal structures, a TEM specimen preparation procedure, which includes a T-tool tripod polishing, and low angle $\left(\sim 2^{\circ}\right)$ and low energy $(0.5-1 \mathrm{kV})$

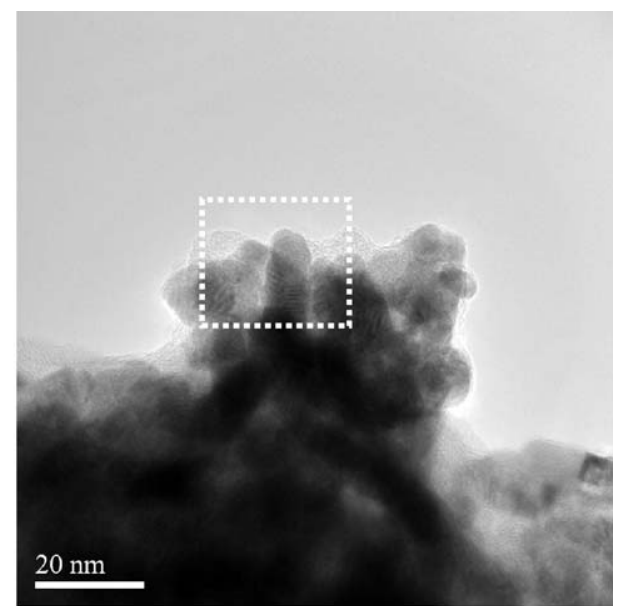

(b)

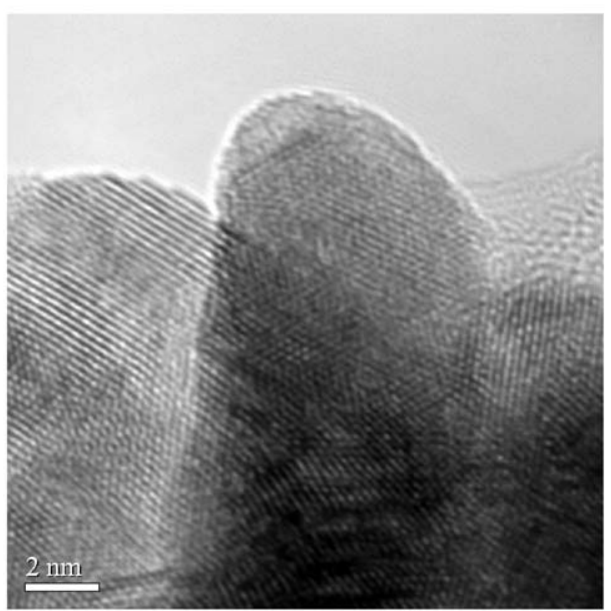

(c)

Fig. 12. The pictures of CNT crystal structures by using a transmission electron microscope (TEM). 
ion milling, has been applied. The measurement was performed using a JEOL JEM-2100F transmission electron microscope (TEM), which is operated at $200 \mathrm{kV}$ and is equipped with a Schottky-type field-emission gun. The point-to-point resolution is $1.9 \AA$. Fig. 12(a) shows the cross-sectional TEM image of the CNT specimen, where the MWCNT are indicated by the arrowhead. Fig. 12(b) is a magnified picture of the dotted area in Fig. 12(a). Fig. 12(c) indicates that the crystal structures are multi-wall carbon nanotubes. The graphite layers of CNT are between 10 and $20 \mathrm{~nm}$. The top ends of these CNT contain the particles of metal carbide or metal catalyst.

Note that the radii and the lengths of synthesized CNT by using the technique in this work are relatively non-uniform when compared with the results by using the traditional CVD CNT furnace. We speculate that this difference is due to the flow behaviors of the reactant gases (e.g., micro fluidic and thermal effects) in the micro reaction chamber. In addition, in our electro-thermal simulation model, we assume that the air surrounding the device is stationary (i.e., natural convection boundary condition). However, in the reaction chamber, the reaction gases flow through the microchannels at certain velocity. Certain portion of the heat generated by the microheater will be dissipated by the "forced convection" effect. Therefore, the gas-flowing effect is the possible reason why the experimental heating voltage is higher than the simulated results. Further study on the gas flow behaviors as well as temperature control is under way.

\section{Conclusions}

This work demonstrates a novel synthesis process for selectively locally growing nanowires on a microreactor chip that is fabricated by MEMS technologies. The developed process allows nano-device engineers to control the location of the CNT materials. The microreactor chip consists of a microheater structure and a micro-reaction chamber by anodically bonding a Pyrex cap on a chip carrying the microheater structure. The microheater contains a titanium layer of $500 \mathrm{~nm}$ in thickness and a nickel catalyst about $30 \mathrm{~nm}$ in thicknesses. The CNTs were successful synthesized by the low temperature CVD methods on the microheater and only $7 \mathrm{~V}$ input voltage is required to be applied on the microheater. The supplied gases, which include $\mathrm{H}_{2}, \mathrm{Ar}$, and $\mathrm{C}_{2} \mathrm{H}_{2}$, react with the nickel catalyst to synthesize CNTs. The crystal structures and dimensions of CNT were observed by a FESEM and a TEM. Higher distribution of the synthesized CNT diameters is in the range from 13 to $21 \mathrm{~nm}$. The average diameter of CNT is $16.93 \mathrm{~nm}$. The lengths of the synthesized CNT are about $100-200 \mathrm{~nm}$. Besides, the CNTs grow on the center region (about $30 \mu \mathrm{m} \times 30 \mu \mathrm{m}$ ) of the microheater $(50 \mu \mathrm{m} \times 50 \mu \mathrm{m})$, which is consistent with the thermal analysis results.

This work has shown the feasibility of synthesizing CNT in a microchamber by demonstrating the functionality of proposed microreactor chip. This approach is a low temperature process and can effectively avoid heating up the whole chip during the CNT synthesis process. Therefore, it is potentially compatible with IC processes and permits the integration of CNTs to
IC devices. The applied voltages to each microheater and the react gases to each microchamber can be controlled separately. This allows the synthesized CNTs can be highly uniform from chamber to chamber and provide the solution to the critical nonuniform problem encountered in large size CNT field emission displays (FED).

\section{Acknowledgements}

The authors want to appreciate the financial support of Industrial Technology Research Institute (ITRI) with the research project number of A331XS2Y30, and the partial support by the NSC with contract no: NSC 93-2213-E-002-038.

\section{References}

[1] S. Iijima, Helical microtubules of graphitic carbon, Nature 354 (1991) $56-58$.

[2] D.S. Bethune, C.H. Kiang, M.S. deVries, G. Gorman, R. Savoy, J. Vazquez, R. Beyers, Cobalt-catalysed growth of carbon nanotubes with single-atomic-layer walls, Nature 363 (1993) 605-607.

[3] C. Journet, W.K. Maser, P. Bernier, A. Loiseau, M.L. Delachapelle, S. Lefrant, P. Deniard, R. Lee, J.E. Fischer, Large-scale production of single-walled carbon nanotubes by the electric-arc technique, Nature 388 (1997) 756-758.

[4] A. Thess, R. Lee, P. Nikolaev, H. Dai, P. Petit, J. Robert, C. Xu, Y.H. Lee, S.G. Kim, A.G. Rinzler, D.T. Colbert, G.E. Scuseria, D. Tománek, J.E. Fischer, R.E. Smalley, Crystalline ropes of metallic carbon nanotubes, Science 273 (1996) 483-486.

[5] K. Liu, M. Burghard, S. Roth, P. Bernier, Conductance spikes in singlewalled carbon nanotube field-effect transistor, Appl. Phys. Lett. 75 (16) (1999) 2494-2496.

[6] W.B. Choi, S. Chae, E. Bae, J.-W. Lee, B.-H. Cheong, J.-R. Kim, J.-J. Kim, Carbon-nanotube-based nonvolatile memory with oxide-nitride-oxide film and nanoscale channel, Appl. Phys. Lett. 82 (2) (2003) 275-277.

[7] T. Kim, J.-M. Zuo, E.A. Olson, I. Petrov, Imaging suspended carbon nanotubes in field-effect transistors configured with microfabricated slits for transmission electron microscopy, Appl. Phys. Lett. 87 (173108) (2005) 1-3.

[8] M.H. Yang, K.B.K. Teo, W.I. Milne, D.G. Hasko, Carbon nanotube Schottky diode and directionally dependent field-effect transistor using asymmetrical contacts, Appl. Phys. Lett. 87 (253116) (2005) 1-3.

[9] O. Englander, D. Christensen, L. Lin, Local synthesis of silicon nanowires and carbon nanotubes on microbridges, Appl. Phys. Lett. 82 (26) (2003) 4797-4799.

[10] D. Christensen, O. Englander, J. Kim, L. Lin, Room temperature local synthesis of carbon nanotubes, Nanotechnology, in: IEEE-NANO 2003 conference, 2003, pp. 581-584.

[11] A. Jungen, C. Stampfer, M. Tonteling, S. Schiesser, D. Sarangi, C. Hierold, Localized, CMOS compatible growth of carbon nanotubes on a $3 \times 3 \times \mu \mathrm{m}^{2}$ microheater spot, Solid-State Sensors, Actuators Microsyst. 2005 (1) (2005) 93-96.

[12] E.O. Sunden, T.L. Wright, J. Lee, W.P. King, S. Graham, Roomtemperature chemical vapor deposition and mass detection on a heated atomic force microscope cantilever, Appl. Phys. Lett. 88 (033107) (2006) $1-3$

[13] C.J. Lee, D.W. Kim, T.J. Lee, Y.C. Choi, Y.S. Park, W.S. Kim, Y.H. Leea, Y.C. Choi, Y.S. Park, W.S. Kim, Y.H. Leea, Y.G. Choi, S.C. Yu, Synthesis of uniformly distributed carbon nanotubes on a large area of Si substrates by thermal chemical vapor deposition, Appl. Phys. Lett. 75 (12) (1999) 1721-1723.

[14] C.J. Lee, T.J. Lee, J. Park, Carbon nanofibers grown on sodalime glass at $500{ }^{\circ} \mathrm{C}$ using thermal chemical vapor deposition, Chem. Phys. Lett. $340(5,6)(2001) 413-418$. 


\section{Biographies}

Wei-Chih Lin received his BS and MS degrees in the Department of Mechanical Engineering Tamkang University, Taiwan in 2000 and 2002, respectively. $\mathrm{He}$ worked as an engineer in the Industrial Technology Research Institute (ITRI), Hsinchu Taiwan during 2002-2005. He is currently a PhD student in Department of Mechanical Engineering at National Taiwan University, Taiwan

Yao-Joe Yang received the BS degree from the National Taiwan University, Taipei, Taiwan, in 1990, and the MS and the PhD degrees in electrical engineering from the Massachusetts Institute of Technology, Cambridge, in 1997 and 1999, respectively. From 1999 to 2000, he joined the Coventor Inc., (Cambridge, MA) as a senior application engineer. Since 2000, he joined the Department of Mechanical Engineering at the National Taiwan University, Taipei, Taiwan. Currently, he is an associate professor. He also serves as the director for CAD Technology in the Northern NEMS Center sponsored by the National Science Council, Taiwan. Since 2005, he serves as the co-director of the Opto-Electronics Resource Center (OERC) sponsored by the Ministry of Education, Taiwan. His research interests include microelectromechanical systems, nanotechnology, parallel processing, and semiconductor devices and vacuum microelectronics modeling. He has been consulted by more than three U.S.-based companies and four Taiwan-based organizations. Dr. Yang is a member of IEEE.

Gen-Wen Hsieh was born in Taiwan, in 1975. He obtained his BS and MS degrees in chemistry and chemical engineering from the National TsingHwa University, Taiwan (1999, 2001). In 2002, he joined the Microsystem
Technology Center at the Industrial Technology Research Institute, Taiwan. $\mathrm{He}$ is currently involved in research on scanning cantilever probe sensors, packaging of micromechanical devices, and NEMS.

Ching-Hsiang Tsai received his BS and MS degrees in the Department of Chemical Engineering and Material Science from Chinese Culture University Taiwan (1998, 2000). He worked as an engineer in the Electronics Research and Service Organization (ERSO), Industrial Technology Research Institute (ITRI), Hsinchu Taiwan during 2001-2005. He is currently a PhD candidate of Department of nanomechanics, Tohoku University Japan. His research interests include nano probe, carbon nanotube, and diamond emitter.

Chien-Chen Chen received the BS degree in mechanical engineering from National Taiwan University, Taipei, Taiwan, R.O.C. in 2004. He has been being involved in several research projects sponsored by the National Science Council, Taiwan, R.O.C. His main research interests include numerical analysis, system dynamics/control, and model order reduction techniques.

Chao-Chiun Liang was born in Taipei, Taiwan, on December 27, 1967. He received the BS degree from National Chung Hsing University, Taiwan in 1991, the MS and PhD degrees in National Taiwan University, Taiwan, in 1993 and 2000, respectively, all in mechanical engineering. From 2001 to 2004, Dr. Liang was an engineer of MEMS division, Electronics Research \& Service \& Organization (ERSO), Industrial Technology Research Institute (ITRI), Taiwan. He was in charge of photolithography module and worked for Nano Probe Projects. Since 2005, he has been an engineer of Thin Film Circuit Design \& Application Department, ERSO, ITRI, Taiwan. Currently, he works for MRAM and CNT-FED projects. 